\title{
THE PHILOSOPHICAL CONCEPT OF "UBUNTU" AS DIALOGIC ETHIC AND THE TRANSFORMATION OF POLITICAL COMMUNITY IN AFRICA
}

\author{
Jude Chinweuba Asike \\ http://dx.doi.org/10.4314/og.v12i s1.1
}

\begin{abstract}
This work evaluates the fundamental questions of classical ethics on the possibility of forms of community which are simultaneously more universalistic and more sensitive to cultural differences. The finding of this paper supports the thesis that universalism remain an ethical ideal on which the African state remain viable to transcultural or dialogic ethical relationship within the space of modernity. The transformation of an African communities, kingdoms and empires prior to modernity was rejuvenated in the concept of "Ubuntu", but with the emergence of modernity as reorganization of institutions and social conditions of state in Africa, it confronted each other as geopolitical rivals in the condition of anarchy. Thus, it is on a related note, that globalization with its dialogic ethic would be encouraged to approximate the normative ideal of a universal communication community in African states. Globalization significantly, creates the possibility of forms of community which are simultaneously more universalistic and more sensitive to cultural differences. It is only when the African political community cultivates the spirit of responsible and common citizenship that it is able to sustain its unity and diversity. The paper establishes that, 'Ubuntu' as a set of interrelated concepts appears to invoke the spirit of oneness among cultures in Africa.
\end{abstract}

\section{Introduction}

Contemporary multiculturalism is a form of dialogic ethic transformation of political community. Modernity with its concomitant discords, reorganization of institutions, and social condition of states in Africa during colonization gave all its exigencies to a form of plural society. "A plural society needs to strike the right balance between the demands of unity and diversity, following basic principles under which communities can feel secure, 
and affirm their identity in unforced interactions while ensuring that their members can interact as fellow citizens in a shared public realm" (Parekh, 1997).

Critiques of cosmopolitan morality which accompanied the state of modernity and repudiates the already existing cultures in African viewpoint have no sense of a vision of dialogic community of contemporary time of globalization. They refused to sustain the orientations of the modern political community, by referring to the cultures of their old empires hegemonies. Thus, trying to bridge the hiatus, is an attempt to develop a dialogue, a sort of larger inquiry into the nature and possibility of new forms of political conversation between all variant differences in re-shaping or re-culturing with the new age of reasoning. However, it is in this consideration that the emergence of improved forms of political community will occur in this global age. Then cultural erosions or renegades of cultural relativism will disappear from our time. In corroboration with this, Linklater says that:

The modern society of states may yet out to be the first international society which is not destroyed by conquest and war but transformed peacefully by the normative commitment to extending the normal and political boundaries of the community (Linklater 1998:9)

The main aim of this paper is to develop a critical inquiry into international relations which embraces normative, sociological and philosophical visions towards ideal states in Africa. A commitment to the philosophy of "ubuntu" in sustainable peace building is important as a dialogic ethic transformation of our modern states in Africa. The concept was utilized in the past for consolidations of cultures, and then rationalizations of different subjective and objective relativists into one democratic culture. "Ubuntu" being humanistic, transcending the ethical limitations of sovereign nations-states which is restricted in the light of the contemporary politics of difference enables them to live together.

The situation with respect to "ubuntu" is to use the same process of pre-colonization ideology of moral principles to salvage the crises of modernity in Africa. African cultures are required in 
the development of African institutions. We cannot escape the fact that the principle of exclusions is a negation to humanity. The dialogical transference of the ideological past of African ontology can be utilized as an essence of globalization of culture in African. Hence, this is ontic-ontological nature of our being and aptitudes of 'unfoldingness' in Africa. "Ubuntu" therefore, is an all-embracing African interpretation of both 'negative' and 'positive' peacebuilding which promotes a culture of peace, tolerance, peaceful coexistence and mutual development. It is also based on the principles of reciprocity, inclusivity and a sense of shared destiny between peoples and communities. In practical terms it is about reconciliation and peace building in divided societies on the one hand and about democratic participation in African communities on the other hand.

\section{Conceptual Clarifications}

\section{"Ubuntu"}

The term "Ubuntu" is a word derived from the Bantu language, and has no literal meaning in English Language. It is a concept widely used in the East, Central, North and Southern Africa. The meaning of the word also has reflected in different languages in Africa. In order words, 'ubuntu' sought to invoke the spirit of black African civilization. It is a shared self-understanding and national identity. It is homogeneity, best preserved in the climate of flourishing and selfconfident cultural diversities in Africa. It was opposed to the dependency relationship between colonized and colonist and provided a foundation for revival of African identity. As an ideology, it provided the ground for renewed dialogic interaction formally practiced in Africa before the modernization period (Francis, 2006).

\section{Dialogic Ethic}

Dialogic is a term derived from the word 'dialogue', meaning conversation between two or more individuals, or coming to an agreement to reach a consensus. Bull and Watson have crucial contribution in this respect arguing that: "A society of states was distinguished from a system of states by its emphasis on dialogue 
and consent which facilitated the development of common rules, institution and interests." (Bull and Watson, 1984:1)

The commitment to dialogue is linked with the rationalist analysis in which the society of states provide a dialogic framework for diverse states and cultures. It means an exchange of truth, freedom and politics in relations between ethnocentrism and transcultural validity claims. Efforts to articulate trans-cultural validity claims are means of transcending ethnocentrism in different cultures. It acts as a check to various forms of political and cultural inhibitions in different cultures. Dialogic ethic is the only common ground on which people can get together. It is an agreement to bridge the hiatus or lacuna between people in areas of politics, economic and social fragmentations of ideas within a political community. Dialogic ethic is an ethical convergence which reveals that different civilizations have made moral progress and have determined to live together harmoniously in their lives. It signifies to the importance of a cross cultural judgment in our societies.

\section{Political Community}

Community literally refers to a group of people who share the same locality or interests. In this paper, the term political community is more intimate and concentrated term referring to economic, social and political life of a group of people in civic activities as a consequence of their physical, intellectual, or spiritual proximity. As observed by Habermas, "what once meant by the idea of popular sovereignty is doomed to a mere chimera if it remains locked in the historical form of the self-asserting sovereign nation state" (Habermas, 1994:165). Mouffe, adds that:

The 'ethics political bond' is at odds with communitarian notions of a unifying common good and with the liberal belief that political community consists of elementary 'rules of civil intercourse' which leave individuals at liberty to promote their own interest. (Mouffe, 1993:10)

The state of governance in a political community is the contract or agreement (constitutions) which people enter into only to effect a transaction. Human interaction in many sectors seems governed by 
a calculus of individual benefits and exploitation instead of mutual benefit and reciprocity. Hence, this is the problem confronted by dialogic ethic interaction of political community in Africa.

The terms inclusion and exclusion relate to the importance of dialogic interaction between cultures, with members of symmetrically excluded groups or included groups. The normative importance of universalism of norms is the goal of dialogic ethics. Thus, cultural differences are no barrier to equal right to participation within dialogic community. In order words, dialogic ethics makes everything within its scope to be included or excluded in the area of interest. The term trans-cultural is the idea of extending through more than one human culture. It relates to dialogic interaction among cultures to develop a similar approach to political communities involved. On a related note, Hegel opines that, human beings invested their power in nature and alienated their power to shape social structures to natural forces. Thus, without this function of cross-cultural judgment, the legitimacy of those who wield motions of nature to impose power on others goes unchallenged and the dialogic community would be denied.

\section{Limits of Exclusion: Membership, Citizenship and Global Responsibilities}

Almost all societies today are multicultural, which means that they are heterogeneous consisting of several distinct and self-conscious cultural communities. Thus, a cultural community cherishes their identity and preserves it from extinctions. However, based on this circumstance, how should members of this society deal with questions about the morality of system of exclusion? What criteria should they use to distinguish between justifiable and unjustifiable forms of exclusion? What possibility is there, that they might be able to claim trans-cultural validity for their substantive conclusions or for the procedures by which they are reached?

Whatever the outcome, the paper proposes that, no culture can assume that its moral claims automatically have this transcultural status. Only through dialogue with other cultures can progress be made in separating merely local truths from those with wider acclaim. Again, on the notion of inclusion and exclusion of membership the rights to exclude outsiders as an alien would be 
based on the inabilities of non-compliance to the political, economic and cultural ties. For this reason, Parekh asserts that:

To be a citizen is to be co-sovereign, to be in charge of the part of destiny of one's country along with one's fellow citizens. Citizenship has three dimensions. It is a legal status entailing obvious civil and political rights. It is a political practice, a way of thinking about and participating in the conduct of public affairs. And thirdly, it is a historical relationship, a mode of integrating oneself into the ongoing life of one's community (Parekh, 1997:526).

Deliberating on this will turn out to be that, a political community is not some transcendental entity, but a body of citizens thinking and living in a certain way. A political community shares a common public realm, deliberate about collective affairs in common public language, and relate to each other as member of a specific community. Thus, if this is the case, on what ground, can the societal right of closure be qualified? Walzer on a related note, "argues that:

Exceptional circumstance where necessitous men and women who have been driven by war or famine from their countries of origin clamor for entry into a thinly populated society such as Australia which controls 'great empty spaces' and a tenuous right to the land which was seized from the first inhabitants (Walzer, 1995:46)

Walzer emphasizes that each society must retain its right of self to ensure justice for others. According to him there are no simple answers to questions of inclusion and exclusion which arise in societies which wish to preserve their cultural integrity but recognize moral duty to ethics with the rest of humanity.Arguably, the desire to ensure justice for refugees, and justice for states points towards a basic international obligation to shoulder the responsibility through dialogue with others. The efforts to establish international equity 
would be an encroachment upon the right of the sovereign state to decide questions regarding the distribution of membership on its own accord.

Actually, the level of reflectiveness about practices of exclusion varies considerably between societies. Most societies must also reflect upon the ways the dominant conceptions of citizenship to exclude culturally marginal groups within national boundaries. A commitment to the right of self-determination is required to be shared among all the members of the political community to possess appropriate levels of autonomy. Moreover, the right of these minorities should be protected for the avoidance of conflicts across states and within boundaries in a legitimate state. All these are important measures of dialogic ideal which is required in our time.

\section{The Philosophic Concept of 'Ubuntu'}

"Ubuntu" is an African term that refers to a dialogue interaction of people(s) culture(s). It connotes love, peace, humanistic, holistic building of a political community, positive/negative peace-building, and showing of remorse and repentance. It also embraces the notion of acknowledgement of guilt; asks for and receiving of forgiveness and reconciliation. It is a philosophical concept of vital force which morally pervades in everyone's life to be human. "Ubuntu" is a bond of unity amongst the people of Africa. A person belongs to his community by participating and sharing with others in and outside his community. Every single human being only becomes a truly human being by means of relationship with others in the society. The emphasis here is to establish the imperatives of human existence in the political communities of Africa. It is a vital force of peace in African ontology, which signifies the principles of reconciliations, reciprocity, inclusivity, democracy and humanism. It is a holistic way of unifying everybody in the community. Thus, for one to live effectively in the community, he/she must imbibe the principles of "ubuntu" in his/her lives.

It is useful to note that Africans have formal mode of existence which gives them the status of political communities before the arrival of Euro-Christian tradition and Arabic-Islamic tradition in Africa. The African transformation agenda prior to the modernization period was rejuvenated with philosophical concept of "ubuntu". Perhaps, "ubuntu" philosophy is the first in a series of 
intellectual and political responses to the expansion of Western philosophical thought and Arabic traditions in Africa. The Western philosophical thought more than any other brand developed a flourishing mythology and ideology. However, according to Vanden-Berger, the westernization process is as a result of:

(1). The prevailing forms of capitalist exploitation, notably illustrated by slavery in the New World and incipient colonial expansion in Africa. (2). Social Darwinism which dovetailed with economic liberalism of the late $19^{\text {th }}$ century. Liberal utilization like John Stuart Mills legitimized laissez-faire, which in turn was re-interpreted as a mandate not to interfere with any form of human inequality and suffering. It literally reflected the platonic ideal which would have supported the view that Negroes were slaves as a result of natural selection. (VandenBerge, 1967:57).

The essence of "ubuntu" is to promote a culture of peace, tolerance, peaceful co-existence and mutual development. It is a systematic entrenchment of the people(s) ideology within the society they live. Only in community with others has each individual the means of cultivating his gifts in all directions; only in the community, therefore is personal freedom possible. The alienation of individuals is negations of the lives of the communities. On a related note, Tutu observes that:

Ubuntu" is very difficult to render in a western language. It speaks to every essence of being human. When you want to give high praise to someone we say, 'Yu U nobuntu'; he or she has "ubuntu". This means that they are generous, hospitable, friendly, caring and compassionate. They share what they have. It also means that my humanity is caught up, is inextricably bound up, in theirs, we belong to a bundle of life. We say 'a person is a person through other people' ("in Xhosa Ubuntu ungamntungabanyeabantu and in Zulu 
Umuntungumuntungumuntungabanye"). I am human being because I belong, I participate, I share. A person with "ubuntu" is open and available to others, affirming of others, does not feel threatened that others are able and good... (Tutu, 1999:10).

Thus, to draw an inference with 'ubuntu' would mean to become a point of reference with Marxism. Marx philosophy therefore, is like the philosophical ideas of 'Ubuntu' striving to rationalize society through the individual participation and activities in the societies. Corroborating this, Soccio in opinion of Marx observes that:

Society will at least be able to provide decent, meaningful lives to virtually everyone. As a result no one will need private property or wealth. Instead of having to compete for a good life, we will live harmoniously, doing creative, satisfying work that benefits us individually at the same time it benefits society collectively. There will be only one class, hence no class conflict. The economy will reach a state of balance and history as such, class struggle will end. (Soccio, 2001:399)

Thus, it is from the virtue of the above, that one considers the political and ideological tendency underlying in "ubuntu" and Marxism. Historical materialism for Marx, represent the basic theory and method which he used in study of history to demonstrate the truth of his prediction of an inevitable class war between the proletariats and the capitalists. With this therefore, the classical point of divergence with "ubuntu" is that Marxism, as a western ethical value is based in single social context for contemporary cultures and enrichment purposes. On the other hand, "ubuntu" is considered to be more fundamental to the life of everyone in the political community. Relating to this, Ortega in the "Revolt of the Masses" asserts that:

The fundamental radical truth is the co-existence of myself with the world. Existing is first and foremost co-existing- it is I myself seeing something which is 
not myself, it is I loving another being, it is I suffering from things (Ortega, 1966:231-232)

We surely would not be wrong to synchronize the Ortega's existentialism with that of "ubuntu's", African existential analytics. Both have the cognitive vision of the world as one entity. In view of Ortega, both the subject and object are united in nature, but they are relatively pure independent from the other. Hence, for "ubuntu" and as well as Ortega, to have a cognitive vision of the world is to exist for the world. Every existence is entirely not without the subject and object; both are compliment of the other, which means that they are in constant conjunction.

It is within these philosophical trajectories that we see "ubuntu" as a philosophical transformation of the political communities in Africa. Life is subjective striving of individual in the society, and the vocation of self is mainly meant for the self-realization in the community of self-shared understanding and diversity.

We are consequently facing a paradoxical situation -that is, while we are nursing the ambitions of African hegemony with the ideal of "ubuntu" as a sign of African imperative for institutional development, the problems now lie with the defects in our hegemony as a result of modernity with its re-organization of institutions in Africa, which realigned the people(s) into different modes of cultures. How then should we re-organize the differences or fragmentations created as a result of modernity in Africa? Thus, Green observed:

Cultural differences reflect not only a history but also fundamental variations in what people hold to be worthwhile. As long as variations persist they will invite comparison and questioning of the practices and preferences of others. It may be disconcerting to have to acknowledge that members of historically stigmatized racial and ethnic groups often do things their way not just because they have been excluded from main stream institutions by prejudice and discrimination, but because they find the values and institutions of the larger society inferior to their own (Green, 1999:5). 
By articulating the pressure of racialized subordination or tribal sentiments, the preferences for cultural homogeneity of dialogic ethic relations are really needed for harmonious living in Africa. For this reason, "ubuntu" would be sought to provide the bases for cultural unity among cultures in Africa. The conceptualization of "ubuntu" as a peace building process in Africa, is not only in the absence of war, conflict, violence, fear, destruction and human sufferings, but also in recapitulation of the absence of unequal and unjust structures, and cultural practices about security, democratic participation, respect for human rights, developments, social progress and justice" (Francis, 2006:27).

However, some critical issues that emerged with this concept of "ubuntu" are its justifications with the Western philosophical thought. The ideological and cultural specific conception of human rights is from the point of view of communication relations. The western approach to human rights stresses on 'individualism' but Africa is 'Universalistic' in its approach to human rights. A very explicit argument here is that in Africa, the clash is obvious between the specificity of rights of the Western philosophical thought and the universalistic rights of the African philosophical thought which are in juxtaposition to each other. It is useful to remember that cultural and racial variations are among the most enduring characteristics of our age in modernity. Thus, diversity is certainly a fact to build within a dialogic ethic transformation for development of African states.

\section{The Dialogic Community: The Perspective of "Ubuntu"}

The goal of dialogic relations with the members of systematically excluded groups is the normative ideal of trans-cultural society. It is necessary to enlarge the boundaries of the community to engage non-nationals as equal in open dialogue, and membership of wider political aspirations. Perhaps, in avoidance of assumed cultural differences, there is no barrier to equal rights of participation within a dialogic community. The underlying principle therefore, is that there are no compelling differences between human beings in which they may seek for exclusion from dialogic interaction. 
The general indication at this juncture is that, the moral rectitude accrued from the essence of the dialogical ethic between the two groups; those that are inside and those that are outside, will encourage developments in the trans-cultural societies. Thus, the only way to justify a moral progress is to extend the boundaries of community. This will bring development within the liberal realm of contingent beliefs. It is a test of open dialogue with others. Corroborating this, Linklater asserts that:

In this case dialogue will require a considered analysis of the extent to which specific cultural differences are morally significant from the vantagepoint of ethics of rescue. If genuine dialogue is to exist no particular outcome can be anticipated or presupposed (Linklater, 1997:86.)

Given this background of the logic of cultural differences or transcultural relations, the pre-colonial African Empire has the practices of dialogic ethics amongst their members' empires. The political communities in Africa have not repudiated these practices which were confronted by emergence of modernity and its re-organization of institutions and social conditions of state. Hence, the moral relativity of the new structure of modernity brought some changes in Africa. In fact, since independence in the 1960's, modernity brought some changes which reflected on cultural/trans-cultural relations in Africa. A notable example is the concept of "ubuntu" which is no longer active in the peace-building relations across communities in Africa.

However, the logic of the African belief system with this dialogic ethic is the criteria of justice and equity in African states. It is humanistic and holistic conception of peace. According to Francis:

It embraces the notion of acknowledgement of guilt, showing of remorse and repentance by perpetrator of injustice, asking for and receiving forgiveness, and paying compensation or reparation as a preclude for reconciliation and peaceful co-existence. The ethical dimension here is based on the moral altruism and dialogic interactions of the 
participatory shared cultures in Africa. This is because of the fact that "ubuntu" is based on the principles of reciprocity, inclusivity and a sense of shared destiny between peoples and communities. The "ubuntu" tradition, in practical terms is about reconciliation and building peace in divided societies and about democratic participation (Francis, 2006:27).

On a related note Shutte asserts that the subject of "ubuntu" is a very important issue in Philosophy. "For example, explore the importance of 'ubuntu" in African Philosophy, especially in areas such as morality/ethics, epistemology, logic and metaphysics (Shutte 2001:47)

Following this philosophical concept of "Ubuntu" as a humanistic Philosophy, then we can come to a summary that "Ubuntu is a Philosophy of African Tribes that can be summed up as I am what I am because of who we are" Tutu,( 2012:2). This indication is very supportive to the idea of dialogic ethical transformations of the global world societies into one united whole. Perhaps, what have been world problems today had already been resolved in Africa many centuries ago in Africa. In the concept of' Ubuntu", there exists every human being an enormous wellbeing of potential. Thus, within that wellspring of potential lies individual sources of empowerment and social harmony, through the realizations human consciousness, compassion, creativity, collaboration, and competence in all our individual and cultural expediencies' It is through the activating them that human beings are survived.

In consideration with this and by drawing an inspiration from Marx, the concept of exclusion or alienation is not very much permissible in African ontology. In Africa prior to colonial period there were "absence of unequal and unjust structure, and cultural matrix about security, democratic participation, social progress and justice" (Francis, 2006:28). The ambiguity of modernity, figures prominently in the disfigurement of African states by changing the value of inclusivity associated with the communal relations in precolonial Africa. The trans-cultural or dialogic interactions of the new age of globalization would now become the modern "ubuntu" in 
Africa. It will also support the rights of already existing African community, which evolves with the "ubuntu".

\section{Conclusion}

The mode of universalistic reasoning which presupposes the reality of this paper is first of all no longer enjoying much support. Secondly, the commitment to the idea of universal conception of good life has fallen into disrepute. Moreover, the demise of traditional universalistic ethics does not justify the conclusion that 'anything goes' in the era of post-metaphysical thinking. More importantly, the structures of the postmodern thinking are entirely new structures of dialogue which require new sets of metaphysical thinking in restructuring the world's communities.

Perhaps what is true as essence of 'ownership and identity' is the cause of the current global crises of the age between different civilizations and ideologies. The outcome of the dialogic ethic relations among variant cultures in the world today, have not yet resulted in positive responses of peace. It is still very contestable in reaching the desired goals. The dialogic communities in which members choose to live together have not yet been established in the same framework of expected trans-culturalism. The wider universalities of discourse necessarily take several different forms which are required to bring the harmonious living of the age. It is the framework of wider universability accrued from the dialogic relation that will challenge the forms of exclusion in the political community. "Ubuntu" as a formidable structure of peace-building in Africa will be viable instrument of dialogic ethic transformation in modern time.

\section{Recommendations}

Despite the shaking foundation for proper dialogic ethic transformation in Africa, the paper made the following recommendations which would be influential in re-awakening the African consciousness of "ubuntu" as a panacea for genuine transculturalism in Africa.

1. For genuine trans-cultural relations to occur, balanced view of the past must be encouraged. 
Asika: The Philosophical Concept of "Ubuntu"...

2. "Ubuntu" is important, but may remain ineffective and contentious unless it enjoys popular legitimacy in our modern time. The idea of inclusivity is central to democracy; but must be transcended and moderated by a deeper sense of common citizenship.

3. "Ubuntu" as emblematic symbol of oneness does not require cultural homogeneity which must be nuanced for it effective actualization. 


\section{References}

Bull, H. and Watson, A (eds.), (1984). Expansion of international society. Oxford: Clarendon Press.

Francis, D. J. (2006). Peace and conflict studies: An African overview of basic concepts. In G. B. Sheelrack (ed.), Introduction to Peace and Conflict Studies in West Africa, (pp.15-34), Abuja: Spectrum Books Ltd.

Green, J .W. (1999).Cultural awareness in the human services:A multi-ethnic approach. Massachusetts: Allyn and Bacon.

Habermas, J. (1994). The past as futures.Cambridge: Polity Press.

Linklater, A. (1998). The transformation of political community. Columbia: University of South Carolina Press/Blackwell Pub. Ltd.

Mouffee, C. (1993). The return of the politicalcommunity. London: Verso.

Parekh, B. (1997).Managing multicultural society.Commonwealth Journal Affairs, The Round Table. Issue (344), 523-532.

Soccio, D. J. (2001).Archetypes of wisdom.An introduction to philosophy: Belmont: Wadsworth/Thomson Learning.

Shutte, A. (2001). Ubuntu: An Ethic for a New South Africa .Pietermaritzburg: Cluster Publications,

Tutu, D. (1999). No future without forgiveness London: Rider

Ortega, G. (1966). Mission of the university. New York: W. W. Norton and Co. Inc.

Walzer, M. (1995).Spheres of justice:A defense of pluralism and equality. Oxford: Blackwell Publishers.

Vanden-Berger, P. L. (1967). Raceand racism: A comparative perspective. New York: John Willey.

Tutu (2012) http://morvensloblog.word

personpress.com/2012/04/23/ubuntu-a-lesson-from-the-childen 